\title{
Modeling tracer injection and well-aquifer interactions: A new mathematical and numerical approach
}

\author{
Serge Brouyère \\ Hydrogeology, Department of Georesources, Geotechnologies and Building Materials, University of Liège, Liège, Belgium \\ Received 30 October 2002; accepted 4 February 2003; published 26 March 2003. \\ [1] A new mathematical and numerical approach is presented to model solute exchange \\ between a well and the surrounding aquifer for the interpretation of field tracer tests. On \\ the basis of water and tracer mass balance equations integrated over the volume of \\ water in the well, the approach allows for finite volumes of tracer fluid and water flush. \\ It deals with tracer mixing and capturing in the well bore, local distortion of the flow \\ field around the well, and possible tracer back-migration into the well. A numerical \\ solution, implemented in the three-dimensional finite element groundwater flow and \\ transport simulator SUFT3D, is proposed that allows for modeling nonuniform \\ distributions of tracer mass fluxes along the well screens related to variations in aquifer \\ hydraulic conductivity. Showing its ability to reproduce concentration evolutions \\ monitored in a well during field tracer experiments, considering various injection \\ conditions, validates the approach. INDEX TERMS: 1831 Hydrology: Groundwater quality; 1832 \\ Hydrology: Groundwater transport; KEYWORDS: tracer techniques, tracer injection, groundwater transport \\ modeling
}

Citation: Brouyère, S., Modeling tracer injection and well-aquifer interactions: A new mathematical and numerical approach, Water Resour. Res., 39(3), 1070, doi:10.1029/2002WR001813, 2003.

\section{Introduction}

[2] Tracer experiments are frequently performed to identify aquifer transport processes and to quantify the governing hydrodispersive parameters. Many physical factors, related to experimental conditions and well-aquifer interactions, may lead to a tracer input function that departs strongly from commonly assumed instantaneous or step injection profiles. If not explicitly considered, this can lead to severe misinterpretation of the results. In particular, Gelhar et al. [1992] mention that in terms of dispersivity assessment, a clear definition and control of the tracer input function are important factors for classifying the tracer experiment as reliable. Nevertheless, little attention is usually given to this experimental step or to the accuracy of mathematical or numerical representations of the tracer injection.

[3] A new physically based approach is developed in order to accurately model tracer injection in a well. It is able to account for finite volumes and flow rates of tracer fluid, untraced water flush, mixing and capturing in the well bore, and complex well-aquifer interactions. The possibility of accounting for the influence of aquifer heterogeneity close to the injection well is also discussed. The implementation of the numerical scheme in a groundwater flow and transport numerical simulator (here, in the SUFT3D code) is described. For validation of these developments, the model

Copyright 2003 by the American Geophysical Union. 0043-1397/03/2002WR001813\$09.00 is used to fit concentration evolutions monitored in a well during field tracer experiments.

\section{Main Factors Influencing the Injection Process}

[4] When the tracer is injected in a well, its actual input function in the aquifer may be influenced by several factors. First of all, the duration and flow rates associated with the tracer injection and the water flush can play an important role [Guvanasen and Guvanasen, 1987; Brouyère and Rentier, 1997]. However, the experimenter can control these factors. Other key factors, related to well configuration and well-aquifer interactions, are not directly controlled and are often disregarded.

[5] When the volume $V_{i n j}\left(\mathrm{~L}^{3}\right)$ of tracer is injected, a dilution occurs with the volume of water $V_{w}\left(\mathrm{~L}^{3}\right)$ in the well. In spite of the injection of a water flush, a quantity of tracer may remain temporarily captured in the well bore. These socalled mixing effects that potentially result in lower recovery peaks at observation or pumping wells [Novakowski, 1992a; Moench, 1989] are usually quantified with a nondimensional mixing factor $V_{i n j}^{*}=V_{i n j} / V_{w}$.

[6] When injection operations are completed, the remaining quantity of tracer in the well is progressively released to the aquifer due to the natural-gradient transit flow rate crossing well screens. This flow rate is affected by well bore skin effects, which are often considered by means of a nondimensional lumping distortion coefficient $\alpha_{w}$, expressing the ratio between the actual water flow rate crossing the well section orthogonal to the main flow direction and the theoretical flow rate that would transit across the same 
section if the well was not present [e.g., Drost et al., 1968; Hall, 1996]:

$$
\alpha_{w}=\frac{Q_{t}^{0}}{2 r_{w} e_{s c r}\left|\underline{v}_{D}\right|}
$$

$Q_{t}^{0}$ is the flow rate crossing the well screens $\left(\mathrm{L}^{3} \mathrm{~T}^{-1}\right)$ in natural flow conditions, $r_{w}$ is the screen casing radius (L), $e_{s c r}$ is the screen length (L), and $\left|v_{D}\right|$ is the mean Darcy flux $\left(\mathrm{L} \mathrm{T}^{-1}\right)$ that would prevail close to the well in the absence of flow distortion.

[7] Finally, because of the heterogeneity of the aquifer, the distribution of water fluxes along the screens may lead to a nonuniform tracer spreading in the aquifer, in the vicinity of the injection well.

\section{Mathematical Model}

\subsection{Existing Approaches}

[8] Guvanasen and Guvanasen [1987] have developed a semianalytical solution that deals with a finite volume of tracer fluid and water flush but does not consider well-bore mixing and skin effects. The analytical solutions of Novakowski [1992a] allow for tracer column displacements, considering mixing effects in reservoirs connected to column inlet and outlet, but are limited to the one-dimensional case. The analytical solution of Moench [1989], applied to radially converging tracer tests, considers well-bore mixing effects in the injection and extraction wells, but a Dirichlettype boundary condition is used to link concentrations in the well bore and in the surrounding aquifer. Novakowski [1992b] determined that from a physical point of view, the third-type boundary conditions better represent experimental data. Aside from proposing a correction to the solution proposed by Moench [1989] (see correction to Moench [1989]), Zlotnik and Logan [1996] discuss concentration-based and mass flux-based boundary conditions applied at the interface between the injection well and the aquifer, with the assumption that the tracer injection rate is small and therefore does not alter the velocity distribution in the aquifer around the injection well. Thus actual injection conditions dealing with a finite volume of tracer and water cannot be considered. Several approaches have also been proposed for modeling wells using one-dimensional highly conductive finite elements [e.g., Sudicky et al., 1995; Wu et al., 1996]. Being one-dimensional, these elements do not consider the influence of skin effects on the flow field pattern close to the well.

[9] It appears that none of the existing approaches is able to deal with the full complexity associated with the tracer injection process and actual field conditions. In what follows, a new mathematical model is presented that allows for the tracer injection operations actually encountered in the field to be modeled.

\subsection{Mass Balance Equations Applied to Water and Tracer in the Well Bore}

[10] The model is based on mass balance equations applied to water and solute, integrated over the volume of water $V_{w}$ in the well bore (Figure 1). Flow rate terms account for different possible exchanges between the well and its environment: the injection flow rate $Q_{i n}$, the transit

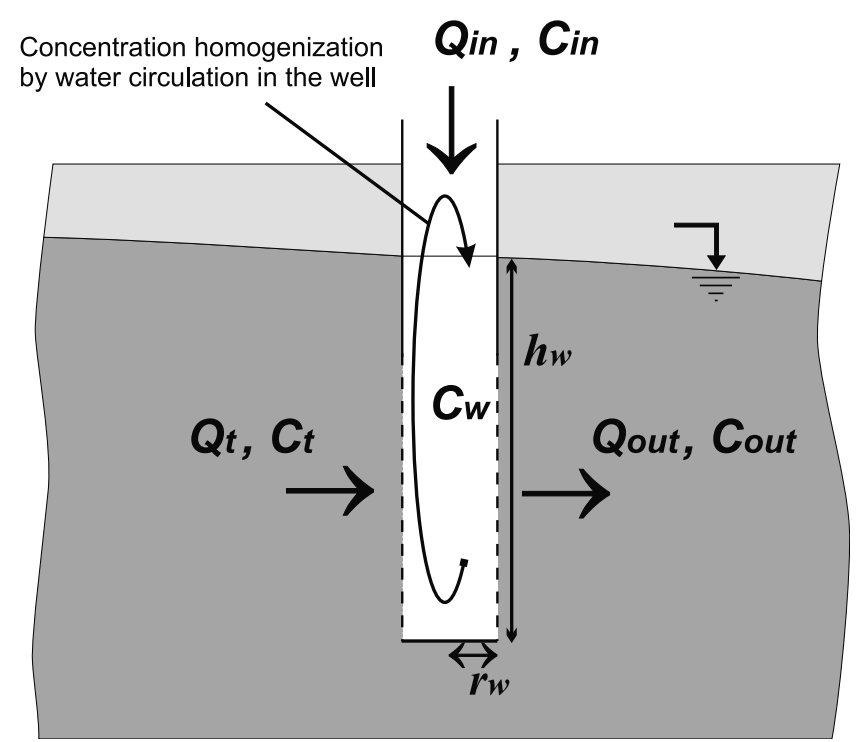

Figure 1. Schematic representation of the well-aquifer system and exchanged fluxes.

flow rate $Q_{t}$ entering the well through the screens, and the flow rate $Q_{o u t}$ leaving the well through the screens. Tracer concentrations associated with these flow rates and in the injection well are $C_{i n}, C_{t}, C_{o u t}$, and $C_{w}$, respectively. All these terms may vary with time. The well radius is $r_{w}$ and the length of the water column in the well is $h_{w}$. If density effects, due to the presence of a solute in the water, are neglected, the mass balance equation applied to water within the well can be written as follows:

$$
\frac{\partial V_{w}(t)}{\partial t}=Q_{\text {in }}(t)+Q_{t}^{\text {in }}(t)-Q_{\text {out }}(t),
$$

where $V_{w}=\pi r_{w}^{2} h_{w}$ is the volume of water in the well at time $t$ and the superscript "in" appearing in $Q_{t}^{i n}$ reflects a dynamic link with $Q_{i n}$ (see section 3.3).

[11] The hypothesis of perfect mixing of the tracer and water in the well bore is assumed. This may be facilitated by pumping water from the bottom part of the well and discharging it at the upper part of the water column. On the basis of that, $C_{w}(t)$ represents the mean concentration in the well at time $t$. It is also assumed that the tracer concentration $C_{\text {out }}$ is equal to the concentration $C_{w}$ in the well.

[12] Finally, the mass balance equation applied to the tracer within the well is given by

$$
\begin{aligned}
\frac{\partial M(t)}{\partial t}=\frac{\partial}{\partial t}\left(V_{w} C_{w}\right) & =\pi r_{w}^{2}\left(C_{w} \frac{\partial h_{w}}{\partial t}+h_{w} \frac{\partial C_{w}}{\partial t}\right) \\
& =Q_{i n} C_{i n}+Q_{t}^{i n} C_{t}-Q_{o u t} C_{w}
\end{aligned}
$$

\subsection{Evaluation of the Transit Flow Rate and Concentration}

[13] The transit flow rate depends on the injection rate. If $Q_{i n}$ is low, $Q_{t}^{i n}$ is close to natural flow conditions (Figure 2a). As $Q_{i n}$ is increased, it progressively diminishes $Q_{t}^{i n}$ (Figure 2b). For a critical value $Q_{i n}=Q_{c r}, Q_{t}^{i n}$ is exactly canceled (Figure 2c). Above the critical injection 


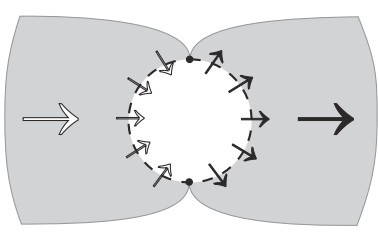

(a) $Q_{\text {in }}=0$

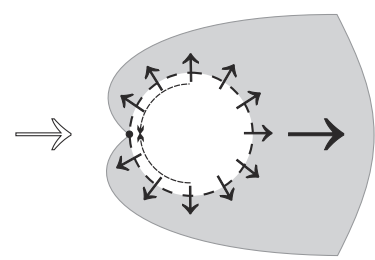

(c) $Q_{\text {in }}=Q_{c r}$

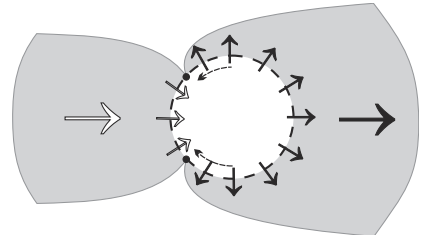

(b) $0<Q_{\text {in }}<Q_{\text {cr }}$

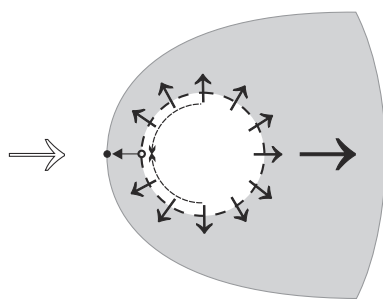

(d) $Q_{\text {in }}>Q_{\text {cr }}$ well capture zone (upstream) / feeding zone (downstream)

- singular point separating portions of the well diameter where water comes in/ flow out across the screens

Figure 2. Modification of groundwater flow lines in the vicinity of the well, according to the injection flow rate $Q_{i n}$.

rate $\left(Q_{i n}>Q_{c r}\right)$, all water leaving the well through the screens is injected water, this water being spread in all directions around the injection well (Figure 2d). To account for the continuous variation of $Q_{t}^{i n}$ according to injection conditions, an analytical formulation has been deduced from the potential theory presented by Bidaux and Tsang [1991]. It can be shown that the resulting equation is given by

$$
Q_{t}^{i n}=2 r_{w} e_{s c r} \alpha_{w}\left|\underline{v}_{D}\right| \sin \left(\arccos Q_{i n}^{*}\right)-\frac{Q_{i n}}{2 \pi}\left(2 \arccos Q_{i n}^{*}\right),
$$

where $Q_{i n}^{*}=Q_{i n} / Q_{c r}$, with $Q_{c r}=2 \pi r_{w} e_{s c r} \alpha_{w}\left|\underline{v}_{D}\right|$ the critical injection rate.

[14] If $Q_{i n}^{*}=0$, equation (4) simplifies to the expected expression for the natural transit flow rate:

$$
Q_{t}=Q_{t}^{0}=\alpha_{w} S_{w}\left|\underline{v}_{D}\right|=2 e_{s c r} r_{w} \alpha_{w}\left|\underline{v}_{D}\right| .
$$

Equation (4) assumes that locally all fluxes reach equilibrium almost instantaneously (i.e., $\partial h_{w} / \partial t=0$ ). This assumption is not valid if the injection rate is very high or if the aquifer hydraulic conductivity or well bore skin permeability is low. However, in this situation, it is likely that the transit flow rate would be canceled.

[15] To evaluate the natural transit flow rate (equation (5)), Darcy velocities prevailing in the aquifer close to the injection well have to be estimated without the influence of any source/sink term applied in the injection well. In a homogeneous aquifer, this can be based on an estimation of the local hydraulic conductivity and gradient. If pure radially converging flow conditions prevail, the following expression can be used:

$$
\left|\underline{v}_{D}\right|=\frac{Q_{P}}{2 \pi d e_{a q}} .
$$

$Q_{P}$ is the extracted flow rate at the pumping well, $d$ is the distance between pumping and injection wells, and $e_{a q}$ is the mean saturated thickness of the aquifer.
[16] During injection and water flush, the transit mass flux $\left(f_{M t}=Q_{t}^{i n} C_{t}\right)$ is set to zero. Indeed, it can be expected that either $Q_{i n}>Q_{c r}$, in which case $Q_{t}$ is equal to zero, or $Q_{i n}$ is low and the transit flux does not carry tracer (i.e., $C_{t}=0$ ). When $Q_{i n}$ is set to zero (tracer injection or water flush completed), it is assumed that $C_{t}=C$, the latter being the mean concentration in the aquifer around the injection well.

[17] Introducing equation (2), expressed in terms of $Q_{\text {out }}$, in equation (3) and considering the different assumptions presented above, the general equation used for modeling tracer injection is

$$
\pi r_{w}^{2} h_{w} \frac{\partial C_{w}}{\partial t}=Q_{i n}\left(C_{i n}-C_{w}\right)+Q_{t}^{i n}\left(C-C_{w}\right) .
$$

Equation (7) shows that the well-aquifer system acts similarly to a dual-porosity system. The injection can thus have some influence on tracer test results due to the capture of tracer in the well bore and gradual release into the aquifer. This may lead to artificially enhanced concentration attenuation and tailing at the observation well [Brouyère, 2001].

\section{Numerical Model}

\subsection{Finite Difference Approximation}

[18] Equation (7) is evaluated numerically, using classical finite difference approximations:

$$
\begin{gathered}
C_{w} \approx \tilde{C}_{w}=\omega_{w} C_{w}(t+\Delta t)+\left(1-\omega_{w}\right) C_{w}(t) \\
\frac{\partial C_{w}(t)}{\partial t} \approx \frac{C_{w}(t+\Delta t)-C_{w}(t)}{\Delta t}
\end{gathered}
$$

where $\omega_{w}$ is a time weighting factor, an implicit scheme $\left(\omega_{w}=1\right)$ being used to guaranty the stability of the numerical computations, and $\Delta t$ is the computation time step.

[19] From the groundwater flow simulation performed prior to execution of the transport problem, the variation of water level in the injection well is linearized on the time step $\Delta t$, as follows:

$$
h_{w} \approx \tilde{h}_{w}=\omega_{w} h_{w}(t+\Delta t)+\left(1-\omega_{w}\right) h_{w}(t)
$$

where $h_{w}(t)$ and $h_{w}(t+\Delta t)$ are the water levels in the well computed at time $t$ and $t+\Delta t$.

[20] These approximations are introduced in equation (7), giving the following expression:

$$
\begin{aligned}
& {\left[\frac{\pi r_{w}^{2} \widetilde{h}_{w}}{\Delta t}+\omega_{w}\left(Q_{i n}+Q_{t}^{i n}\right)\right] C_{w}(t+\Delta t)} \\
& \quad=\left[\frac{\pi r_{w}^{2} \widetilde{h}_{w}}{\Delta t}-\left(1-\omega_{w}\right)\left(Q_{i n}+Q_{t}^{i n}\right)\right] C_{w}(t)+Q_{i n} C_{i n}+Q_{t}^{i n} C
\end{aligned}
$$

With the initial condition for $C_{w}$ and the appropriate values for the injection rate and concentration on the computation 
Table 1. Description of the Injections Performed in Well Pz5

\begin{tabular}{llllllll}
\hline \multirow{2}{*}{ Tracer } & Phase & \multicolumn{1}{c}{$V_{i n j}, \mathrm{~m}^{3}$} & \multicolumn{1}{c}{$T_{i n j}, \mathrm{~s}$} & \multicolumn{1}{c}{$Q_{i n j}, \mathrm{~m}^{3} / \mathrm{s}$} & $V_{f l}, \mathrm{~m}^{3}$ & $T_{f l}, \mathrm{~s}$ & $Q_{f l}, \mathrm{~m}^{3} / \mathrm{s}$ \\
\hline Naphtionate & I & 0.007 & 100 & $7.0 \times 10^{-5}$ & 0.014 & 240 & $5.75 \times 10^{-5}$ \\
& II & 0.003 & 52 & $5.77 \times 10^{-5}$ & 0.100 & 268 & $3.73 \times 10^{-4}$ \\
& III & $0.048+0.152$ & $2400+9900$ & $2.0 \times 10^{-5}+1.54 \times 10^{-5}$ & - & - & - \\
\hline
\end{tabular}

time step, equation (11) fully determines the time evolution of tracer concentration in the injection well.

\subsection{One-Dimensional Representation of the Injection Well}

[21] In some cases, well screens extend over several meters, along which the hydraulic conductivity may vary by orders of magnitude, leading to a nonuniform distribution of injected water and tracer fluxes. In the SUFT3D finite element code [Carabin and Dassargues, 1999; Brouyere, 2001], the approach proposed by Sudicky et al. [1995], for modeling wells using one-dimensional finite elements, is used for distributing the injected water "naturally" among the well nodes. From flow computational results on the current time step, if $n_{w}$ nodes connect the injection well and the aquifer, the different flow rates terms are split into $n_{w}$ components. For example, the injection rate $Q_{i n}$ is split into $n_{w}$ terms $q_{i n}^{K}$, with $Q_{i n}=\sum_{K=1}^{n_{w}} q_{i n}^{K}$. Considering these distributed flow rates, equation (11) can be written

$$
C_{w}(t+\Delta t)=\frac{1}{R_{w}}\left(Q_{i n} C_{i n}+\sum_{K} q_{t}^{K} C_{K}(t)+B_{w} C_{w}(t)\right),
$$

with

$$
\begin{aligned}
& R_{w}=\frac{\pi r_{w}^{2} \tilde{h}_{w}}{\Delta t}+\omega_{w} \sum_{K}\left(q_{t}^{K}+q_{i n}^{K}\right) \\
& B_{w}=\frac{\pi r_{w}^{2} \tilde{h}_{w}}{\Delta t}-\left(1-\omega_{w}\right) \sum_{K}\left(q_{t}^{K}+q_{i n}^{K}\right) .
\end{aligned}
$$

$C_{K}(t)$ is the concentration in the transit flow rate $q_{t}^{K}$ at node $K$ connecting the aquifer and the well. It is taken to be in a fully explicit form in order to relax the dependency of computed concentrations in the aquifer at one connecting node on concentrations in the aquifer at other connecting nodes. This does not influence the stability of the numerical scheme, as the explicit evaluation is performed on a source term and not directly in the transport equation. In this case, Darcy fluxes are computed at the nodes located at the wellaquifer interface, based on flow conditions prevailing before injection begins.

[22] Using a general operator $T_{3 D}(C)$ to represent the numerical form of the transport equation in the aquifer, the following expression describes the implementation of the injection well in the 3-D simulator as a simple source/sink term:

$$
T_{3 D}(C)-\sum_{K=1}^{n_{w}}\left(q_{\text {out }}^{K} C_{w}-q_{t}^{K} C_{K}(t)\right)=0 .
$$

\section{Experimental Validation}

[23] Typical concentration evolutions monitored in the field during field tracer experiments in alluvial deposits and subsequently modeled with SUFT3D are presented as an illustration of the adequacy and accuracy of the modeling approach with respect to field observations.

[24] The studied site is located in the alluvial aquifer of the river Meuse, near Liège, in Belgium. A detailed hydrogeological study including groundwater flow and transport modeling was conducted to study the influence on tracer test results of the injection procedure, local flow conditions, and
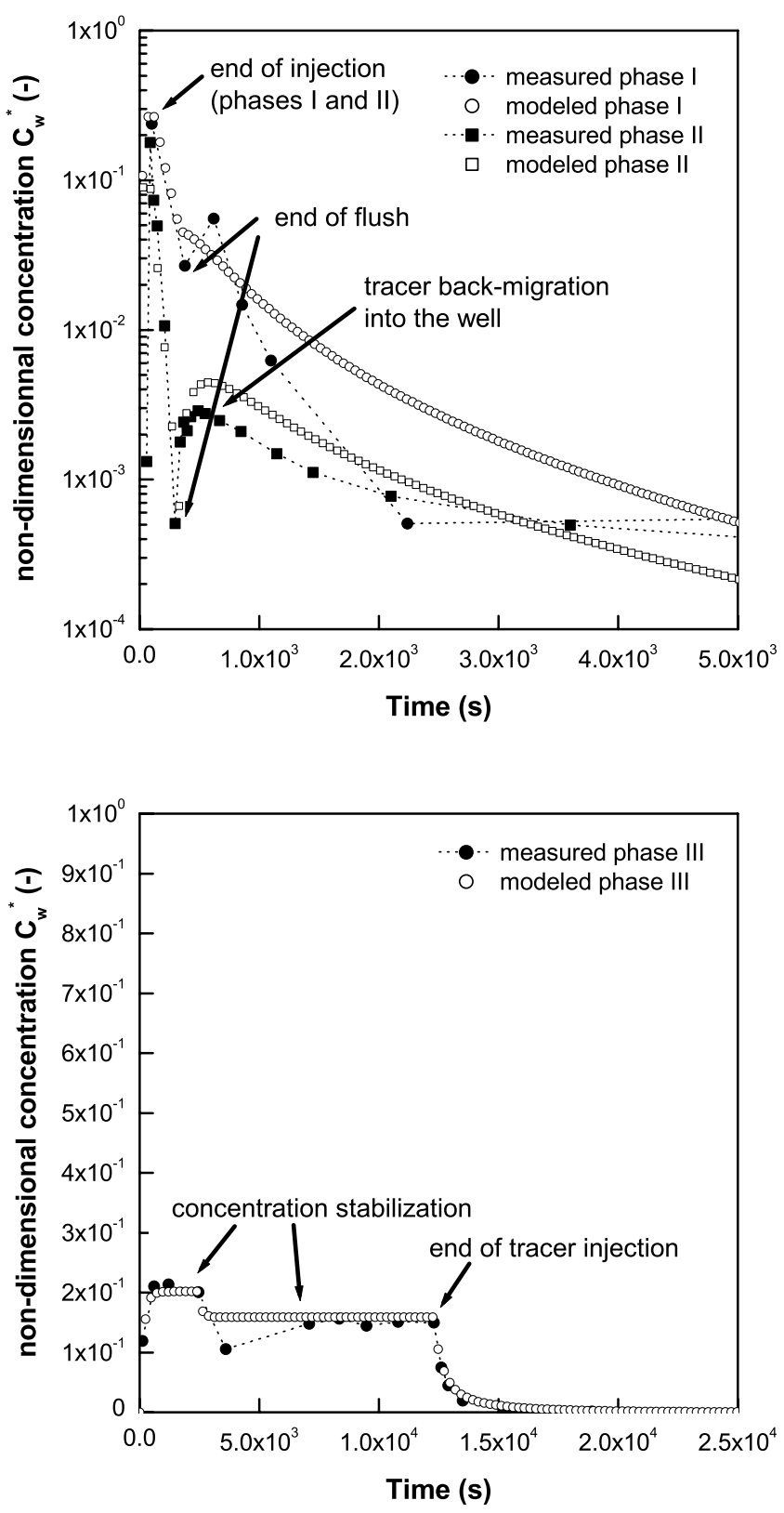

Figure 3. Comparison between concentration evolutions monitored in Pz5 and modeled with the SUFT3D code. 
tracer characteristics [Brouyère, 2001]. Eight injection wells, located at distances ranging from 4.5 to $50 \mathrm{~m}$ from the pumped well (extraction rate, $52.6 \mathrm{~m}^{3} / \mathrm{h}$ ) were used for the tracer experiments. Injections wells have a radius $r_{w}$ of $2.5 \mathrm{~cm}$, and the average length of the water column $h_{w}$ in the wells was $7 \mathrm{~m}\left(V_{w} \approx 13.71\right)$. During each injection, a water circulation was performed in order to homogenize the tracer concentration and to obtain samples at the injection point. To illustrate the proposed methodology, results are presented for well Pz5, located $25 \mathrm{~m}$ away from the pumping well (for details, see Brouyère [2001]). Table 1 summarizes information relative to these injections. Figure 3 shows concentration evolutions monitored in Pz5 together with corresponding profiles computed with SUFT3D. Concentrations are normalized with respect to the concentration in the injected tracer fluid.

[25] During phase I, small volumes and flow rates were used for both the tracer injection and the water flush. During phase II the flush volume and rate were relatively large. During phase III it was decided to perform a "long duration injection," without any flush afterward. For technical reasons, the injection rate was reduced during the injection. Concentration evolutions were adjusted considering $r_{w}$ and $\alpha_{w}$ as fitting parameters. For $r_{w}$, a value of $2.5 \mathrm{~cm}$ was used, equal to the actual well radius, while for the distortion coefficient $\alpha_{w}$, a value of 11.5 was found. This last value is relatively high. However, the distortion coefficient may be viewed as a "correction" factor used to fit the actual transit flow rate across well screens. Furthermore, all injection wells were drilled with a bit diameter $\left(d_{\text {drill }}=11.5 \mathrm{~cm}\right)$ larger than the casing $\left(d_{\text {casing }}=5 \mathrm{~cm}\right)$. The annular space, filled with a gravel pack of high hydraulic conductivity, may induce a strong convergence of flow lines around the well.

[26] For phases I and II the maxima of concentrations observed at the end of the tracer fluid injection and the decrease of concentration observed during the water flush are well reproduced. During phase II the tracer backmigration observed in Pz5 is also well reproduced. During phase III, the concentration in Pz5 stabilizes at a value lower than in the injected fluid $\left(C_{w}^{*}<1\right)$, indicating that a transit flow rate exists and contributes to flush the tracer. When the injection rate is reduced, the transit flow rate is increased, contributing to enhanced dilution of the tracer in the injection well and the stabilization of concentration at a lower level. In addition, the computed concentration evolution remarkably reproduces the dynamic variation of concentration with respect to the equilibrium between injection and transit flow rates, suggesting that equation (4), linking the injection and transit flow rates, is accurate.

\section{Conclusions}

[27] A new conceptual and mathematical approach is proposed for modeling tracer concentration evolution in wells and the solute mass flux leaving or crossing the well at the screen level. It is validated by modeling concentration evolutions monitored in the field during tracer experiments. Contrary to previous approaches, this physically based model considers all processes that can have some influence on solute exchange between a well and the surrounding aquifer: finite volumes of tracer and flush, mixing and skin effects, back-migration of the tracer in the well bore, and heterogeneity of aquifer materials close to the injection well.

[28] Acknowledgments. The Ph.D. research of S. Brouyère was supported by a 4-year grant provided by the Funds for Scientific Research of Belgium. The author would thank Rob McLaren, Ed Sudicky, and René Therrien for their help during a stay in the Department of Earth Sciences of the University of Waterloo, with a travel grant provided by the Ministry of Education and Scientific Research of the French-Speaking Community Government of Belgium, and Jean Houard, Varut Guvanasen, and Allen Moench for their review of the English and their comments.

\section{References}

Bidaux, P., and C.-F. Tsang, Fluid flow patterns around a well bore or an underground drift with complex skin effects, Water Resour. Res., 27(11), 2993-3008, 1991

Brouyère, S., Study and modelling of transport and capturing of solutes in variably saturated media (in French), Ph.D. thesis, 572 pp., Fac. of Appl. Sci., Univ. of Liège, Liège, Belgium, 2001.

Brouyère, S., and C. Rentier, About the influence of the injection mode on tracer test results, in Tracer Hydrology 97, edited by A. Kranjc, pp. $11-$ 17, A. A. Balkema, Brookfield, Vt., 1997.

Carabin, G., and A. Dassargues, Modeling groundwater with ocean and river interaction, Water Resour. Res., 35(8), 2347-2358, 1999.

Drost, W., D. Klotz, K. Arnd, M. Heribert, F. Neumaier, and W. Rauert, Point dilution methods of investigating groundwater flow by means of radioisotopes, Water Resour. Res., 4(1), 125-146, 1968.

Gelhar, L. W., C. Welty, and K. R. Rehfeldt, A critical review of data on field-scale dispersion in aquifers, Water Resour. Res., 28(7), 1955-1974, 1992.

Guvanasen, V., and V. M. Guvanasen, An approximate semianalytical solution for tracer injection tests in a confined aquifer with a radially converging flow field and a finite volume of tracer and chase fluid, Water Resour. Res., 23(8), 1607-1619, 1987.

Hall, S. H., Practical single-well tracer methods for aquifer testing, in Tenth National Outdoor Action Conference and Exposition, Natl. Groundwater Assoc., Colombus, Ohio, 1996.

Moench, A. F., Convergent radial dispersion: A Laplace transform solution for aquifer tracer testing, Water Resour. Res., 25(3), 439-447, 1989. (Correction, Water Resour. Res., 32(5), 1457, 1996.)

Novakowski, K., An evaluation of boundary conditions for one-dimensional solute transport, 1, Mathematical development, Water Resour. Res., 28(9), 2399-2410, 1992a.

Novakowski, K., An evaluation of boundary conditions for one-dimensional solute transport, 2, Column experiments, Water Resour. Res., 28(9), 2411-2423, 1992b.

Sudicky, E. A., A. J. A. Unger, and S. Lacombe, A noniterative technique for the direct implementation of well-bore boundary conditions in threedimensional heterogeneous formations, Water Resour. Res., 31(2), $411-$ 415, 1995.

Wu, Y. S., P. A. Forsyth, and H. Jiang, A consistent approach for applying numerical boundary conditions for multiphase subsurface flow, J. Contam. Hydrol., 23, 157-184, 1996

Zlotnik, V. A., and J. D. Logan, Boundary conditions for convergent radial tracer tests and effect of well bore mixing volume, Water Resour. Res. $32(7), 2323-2328,1996$.

S. Brouyère, Hydrogeology, Department of Georesources, Geotechnologies and Building Materials, University of Liège, Building B52/3, 4000 Liège, Belgium. (serge.brouyere@ulg.ac.be) 